\title{
RISK ASSESSMENT OF GEAR BOX OF WIND TURBINE USING FMEA APPROACH
}

\section{NAVNEET SINGH BHANGU \& SONIA GROVER}

Assistant Professor, Department of Electrical Engineering, Guru Nanak Dev Engineering College, Ludhiana, India

The use of renewable energy has become imperative worldwide and thus wind energy is becoming attractive source of renewable energy. This reason has led to significant growth of wind-farms in recent years especially in developing countries like India. However, several limitations in context of failure of components are associated with its practical implementation. Considerable downtime has been noticed due to failure of major components in onshore wind turbines. This paper presents the application of Failure Mode Effect Analysis (FMEA) for calculating Risk Priority Number (RPN) and remedial measures have been suggested accordingly. A case study of $1000 \mathrm{MW}$ capacity project set up under the flagship of Suzlon Wind Energy is presented. Most failure intensive component, Gear box, has been considered for application of FMEA. With the aim of improvement of availability and decline of RPN, suitable diagnostic and maintenance measures are presented. The RPN of a wind turbine system has been found to be very useful for the wind plant maintenance engineers.
\end{abstract}

KEYWORDS: Failure, Wind Turbine, Gear Box, Effect Analysis, Reliability \& Risk Priority Number

Received: Oct 02, 2019; Accepted: Oct 22, 2019; Published: Nov 18, 2019; Paper Id.: IJMPERDDEC201961

\section{INTRODUCTION}

Failure Modes and Effects Analysis (FMEA) is a procedure based on particular format for identifying, analyzing and averting component and system level problems before they occur. Hence, it is a widely used engineering approach which can be employed for eliminating foremost system failures [1]. It is a step by step analysis of a subsystem or a system which is used to recognize probable failure modes, their causes, and the effects of these failures [2]. Figure 1 depicts the process of FMEA.

FMEA offers framework in terms of possible failure modes, failure effects and causes of failures intended at preventing failures [3]. FMEA is very beneficial on existing systems, sub-systems and components in context of safety hazards and forced outages [4,5]. The FMEA not only gives quantitative analysis for the systematic identification of possible causes and failure modes but also provides estimation of their relative risks [6].

Best quality and long term reliable products are the demand of the day by consumers. This increased demand leads the manufacturers to improve the quality and reliability through expensive testing and better techniques. FMEA is a methodology to examine problems related to reliability in the early stage of development, where it is easier to take appropriate actions. FMEA provides the manufacturer with the solution that can aid to offer safe, reliable and consumer satisfying products and procedures.

NASA has the credit of onset of FMEA for failure prevention, prediction and reliability requirements in 1963. Later, it was acknowledged and widely executed by Ford Motor [7] in 1977. Since then, it has become a powerful tool for risk and reliability analysis of engineering systems in a wide range 
of industries including automotive [8], foundry [9], manufacturing [10], nuclear [11], construction [12] and many more to mention. Initially, the FMEA should be used during the life cycle of a component to classify failures as the system deteriorates. Later on, learning from the experiences, it may be used at design stage to prevent vital failures [13].

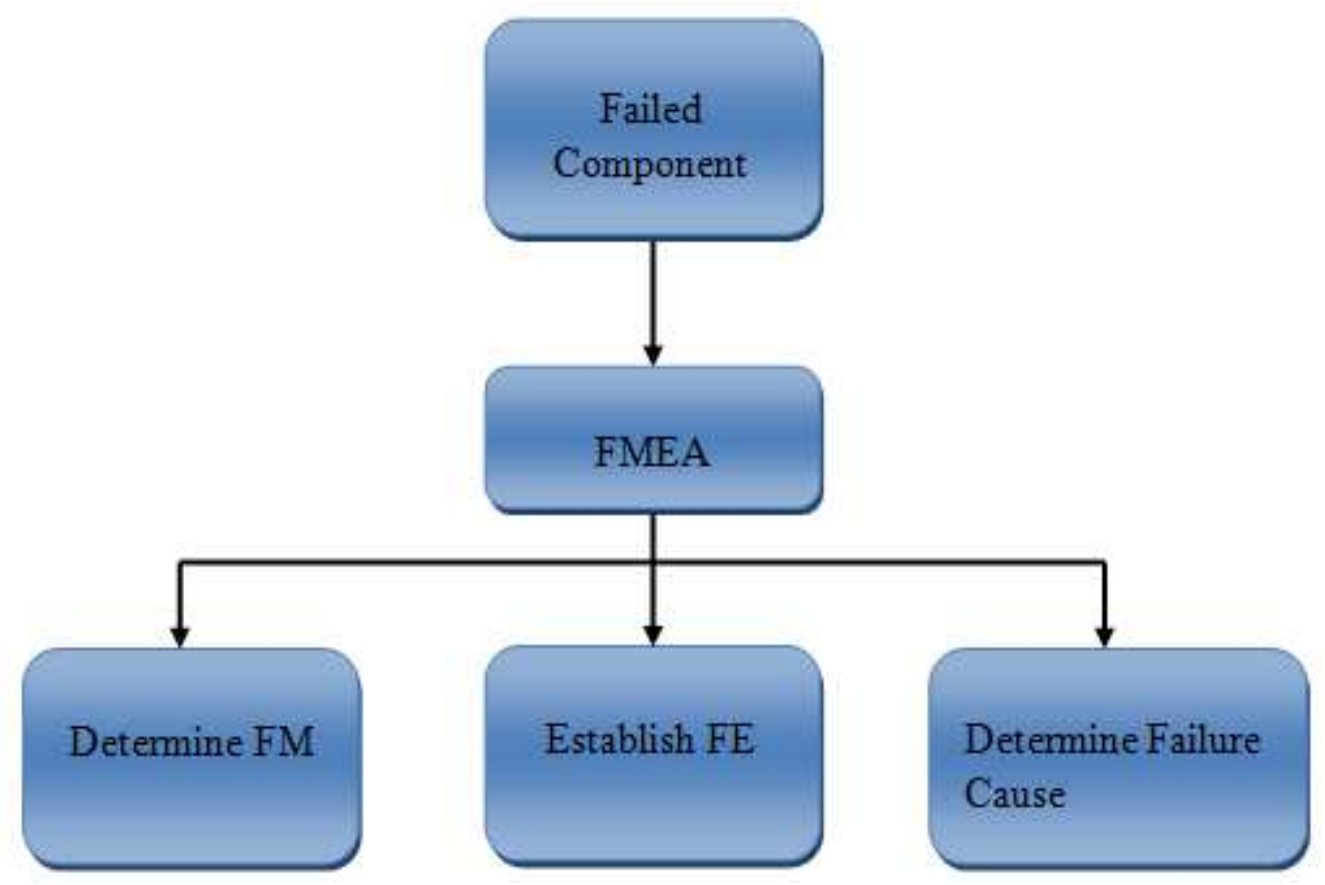

Figure 1: Process of FMEA.

\section{TYPES OF FMEA}

There are numerous types of FMEA, viz-a-viz, System, Design, Process, Service and Software. Out of these, some types are used much more often than others. System and process FMEA are most likely used types of it and can be applied to each and every process unit in a way or so. Conducting FMEA on existing processes, sub-systems and components yields benefits as far as safety hazards and product forced outages or malfunctions are concerned. Many researchers have emphasized on the need of FMEA where failures produce major effect on the components [14]. FMEA can be implemented in a collaborative environment in one organization as a tool that can be used by all departments to assess failure modes and failure effects [15]. According to Keskin and Ozken, FMEA is a technique used in the manufacturing industry to improve production quality and productivity. It is a method that evaluates possible failures in the system, design, process or service. It aims to continuously improve and decrease these kinds of failure modes [16]. The various categories of FMEA are shown in Figure 2.

- System : It mainly focuses on total system functions.

- Software: It involves software related functions/problems.

- Design : It targets design stage of component and subsystem.

- Process : It involves mechanized and assemblage process.

- Service : It is mainly related to service functions. 


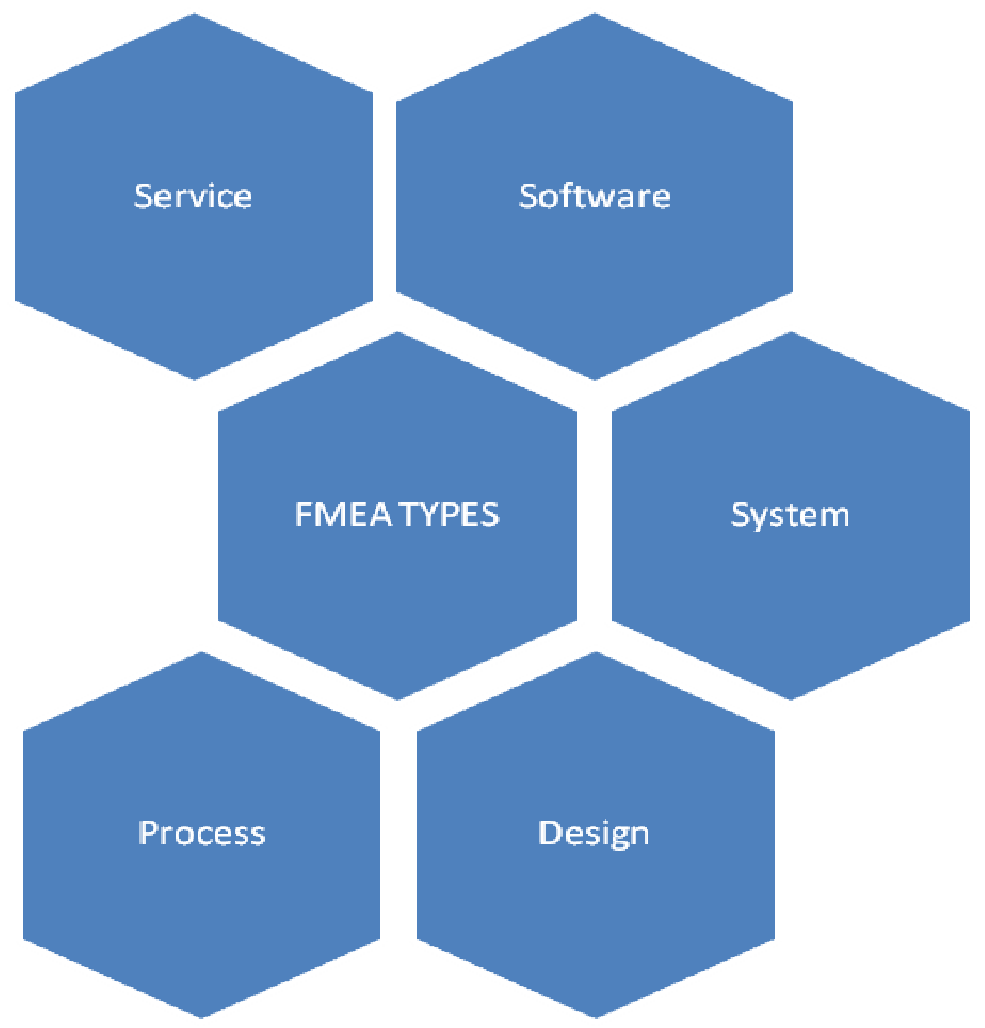

Figure 2: Types of FMEA.

This paper throws light on the purpose of Failure Mode Effect Analysis (FMEA) for calculating Risk Priority Number (RPN) and remedial measures have been suggested accordingly. Wind turbine failure data from a selection of major studies in the literature has been compared and concluded that except the downtimes of gearboxes, other downtimes are not appreciable. The actual failure data collected in this case study is also in line with the observations of most of the researchers. That is why most failure intensive component, Gear box, has been considered for FMEA application. This investigation describes suitable diagnostic and maintenance procedures with the target of improvement of availability of wind turbine and decreasing RPN.

\section{PROCEDURAL STEPS FOR FMEA}

The basic steps to follow for FMEA are as follows:

- First of all, explain the process and its working. It will help the engineer to identify the process uses which fall within or outside the proposed function.

- Secondly, draw a block diagram for the whole process. It should include main parts of process connected by lines which specifies the relation between steps and components.

- Next step is to complete the worksheet that includes product, system, sub-system, components, design, prepared by, etc. The headings can be modified according to the requirement.

- Find out the main failure modes in which a component, sub-system, system process etc. fails to meet the desired output. One failure mode can cause failure in other components and all those failures should be listed in technical term. 
- Explain the effects of failure modes and try to find out each and every effect possible due to a particular failure mode.

- Detect the causes of each failure mode and numerical weightage is given to each cause that specifies probability of cause occurring from 1-10.

- Calculate RPN as product of numerical severity, probability and detection rating

- $\quad \mathrm{RPN}=$ Occurrence $(\mathrm{O}) \times$ Severity $(\mathrm{S}) \times$ Detection $(\mathrm{D})$

- Finally, recommend some actions to address potential failure that have a high RPN. This may include testing, quality procedures, charge in materials, operating conditions. After taking the action, re-assess the severity, probability \& detection and review revised RPN.

\section{APPLICATION OF FMEA}

The application of FMEA technique has been described in this section. The most fault prone component has been found to be gearbox. Figure 3 depicts the vital reasons of failure of sub-components of gearbox i.e. gear and bearing.

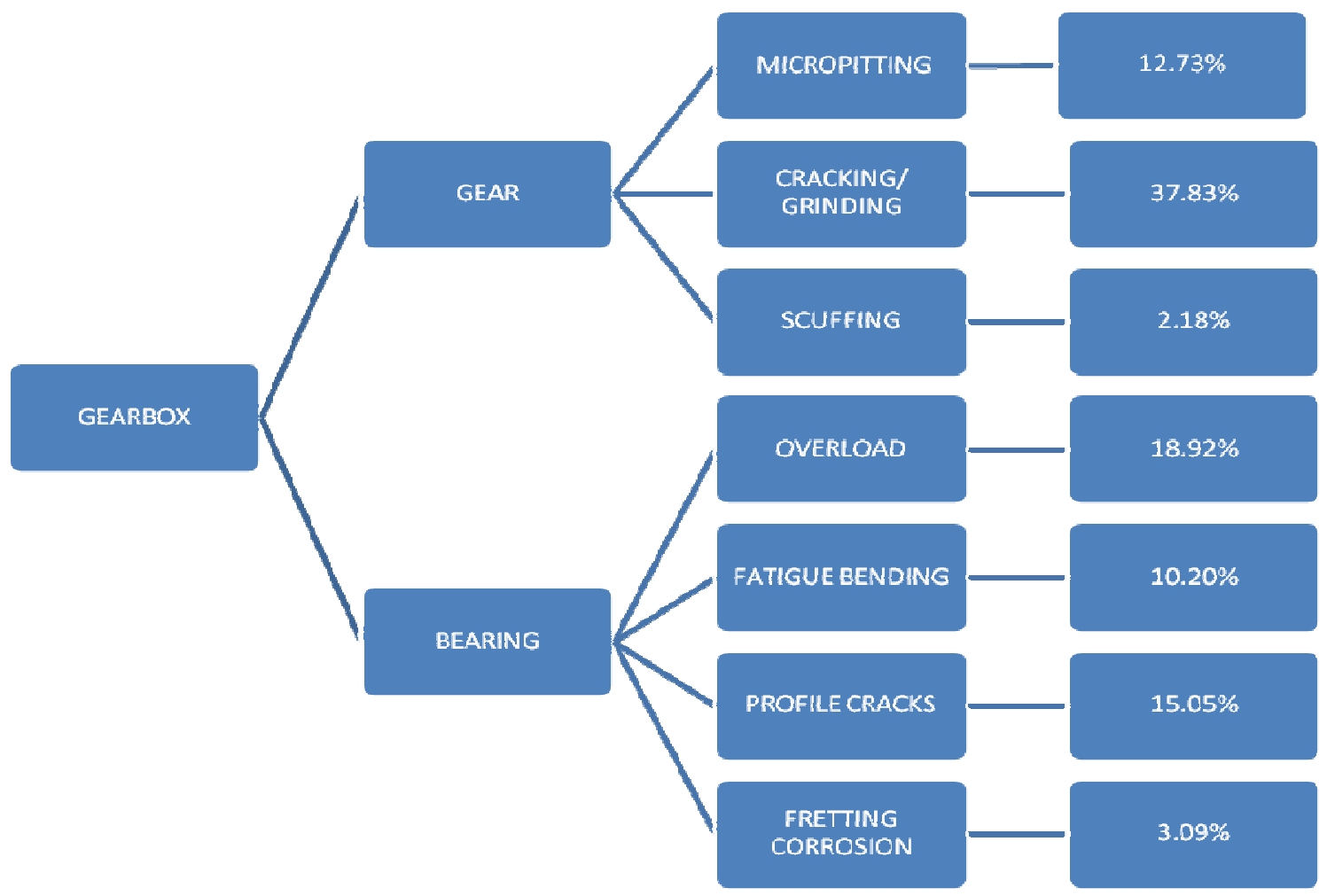

Figure 3: Vital Reasons of Failure of Gearbox.

The major reasons of failure of gear are found to be micropitting, cracking and scuffing. The main reasons of fault in bearing are overloading, fatigue bending, profile cracks and/or fretting corrosion. These reasons have been recorded from field data when failure data of a wind farm has been investigated. Figure 4 shows the percentage contribution of each of failure reason in total down time of gearbox over a period of one year. 


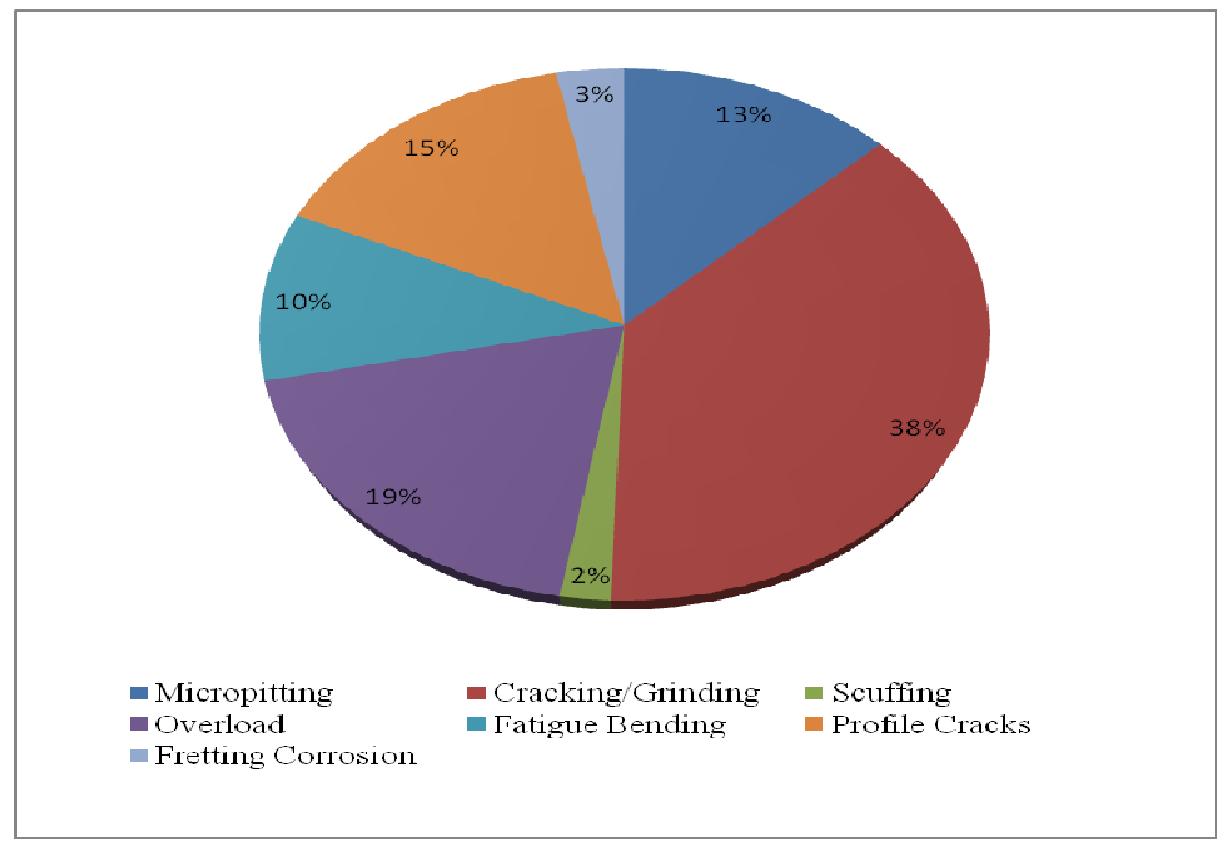

Figure 4: Percentage Contribution of Faults.

\section{FMEA WORKSHEETS}

Table 1 shows the FMEA worksheet for gearbox of wind turbine. This table gives elaborated description of both subcomponents of gearbox i.e. gears and bearings. The function, failure mode, causes and effects of failure along with RPN has been mentioned in the table. FMEA starts with defining the Function of each chosen sub-system or component. It means defining the use of particular component in the system. Failure modes are the ways the component might fail. The next step is to specify all kind of reasonable causes that make a functional failure happen. Lastly, failure effect is defined as result of failure mode on function of the process. It describes what happens when each failure mode occur.

Table 1: FMEA Worksheet for Gearbox

\begin{tabular}{|c|c|c|c|c|c|c|c|c|}
\hline $\begin{array}{c}\text { Item } \\
\text { Description }\end{array}$ & Function & Failure Mode & Failure Cause & Failure Effects & 0 & $\mathrm{~S}$ & D & RPN \\
\hline GEAR & $\begin{array}{l}\text { The actual speed of } \\
\text { rotor is low. Gear } \\
\text { raises the speed to a } \\
\text { high level to be fed } \\
\text { to the induction } \\
\text { generator. }\end{array}$ & $\begin{array}{l}\text { - } \text { Cracking/ } \\
\text { - } \text { Mrinding } \\
\text { formation of very } \\
\text { small, micro-scale pits } \\
\text { or cavities on the } \\
\text { contacting surfaces } \\
\text { - Scuffing i.e. surface } \\
\text { damage of sliding } \\
\text { contact }\end{array}$ & $\begin{array}{l}\text { - Emergency stops and other transient turbine } \\
\text { conditions. It may usually occur due to localized } \\
\text { stresses caused by non-uniform or unequal } \\
\text { transformation of load. } \\
\text { - It occurs due to the surface distress caused by } \\
\text { excessive stress or if lubrication film is not adequate to } \\
\text { separate high-points which are known as asperities. It } \\
\text { occurs on gear teeth. } \\
\text { - Local frictional heating causes scuffing and } \\
\text { deformation of plastic. }\end{array}$ & $\begin{array}{l}\text { Simple causes may lead } \\
\text { to complex damage and } \\
\text { ultimate discount- } \\
\text { inuation of generation } \\
\text { of power. }\end{array}$ & 8 & 9 & 6 & 432 \\
\hline BEARING & $\begin{array}{l}\text { Bearing } \\
\text { supports the blades } \\
\text { and rotor and } \\
\text { transmits torque to } \\
\text { the gearbox }\end{array}$ & $\begin{array}{l}\text { - Overload } \\
\text { - Profile Cracks } \\
\text { - Fatigue Bending } \\
\text { - Fretting Corrosion }\end{array}$ & $\begin{array}{l}\text { - Common transients such as wind gusts, faults in the } \\
\text { grid and braking. } \\
\text { - Profile cracks naturally take place in the inner side of } \\
\text { high speed bearing with age. } \\
\text { - Fatigue Bending basically depends upon two structural } \\
\text { requirements. If these are not met, blades fail } \\
\text { prematurely. } \\
\text { - Fretting Corrosion occurs between contacting surfaces. } \\
\text { Fretting corrosion is caused either by vibration, or by } \\
\text { the micro-motion i.e. when a bearings in the } \\
\text { motionless turbine rock back and forth. It may also } \\
\text { occur when these surfaces are pressed together and } \\
\text { subject to cyclic and/or relative motion of small } \\
\text { amplitude. }\end{array}$ & $\begin{array}{l}\text { Major Damage of } \\
\text { Compo-nent/Tripping }\end{array}$ & 7 & 8 & 5 & 280 \\
\hline
\end{tabular}


After analysing failure mode, cause and effect thoroughly, the remedial measures have been suggested. The Table 2 shows the possible remedial measures for different faults. The RPN number has also been calculated and it has been proposed that it decreases appreciably.

Table 2: Remedial Measures for Gearbox and RPN

\begin{tabular}{|c|c|c|c|c|c|c|}
\hline $\begin{array}{c}\text { Item } \\
\text { Description }\end{array}$ & Failure Mode & Preventive Measures & 0 & S & D & $\begin{array}{c}\text { RPN } \\
\text { (Post } \\
\text { FMEA) }\end{array}$ \\
\hline GEAR & $\begin{array}{ll}\text { - } & \text { Cracking/ } \\
\text { - Grinding } \\
\text { - } & \text { Micropitting } \\
\text { - } & \text { Scuffing }\end{array}$ & $\begin{array}{l}\text { - The life of roller bearings (against cracks) can be improved by selecting quality steel gears at design stage. } \\
\text { By reducing hard insertions and stringers, manufacturers have minimized the probable spaces where } \\
\text { cracks begin and spread. } \\
\text { - The lubricant oil of high quality should be used. Its features rely upon gooeyness index, stickiness, } \\
\text { dispense point and cost. Polyalkyleneglycol (PAG) lubricants have thick Elasto Hydrodynamic } \\
\text { Lubrication (EHL) films and very good micropitting resistance. } \\
\text { - There are two promising methods to reduce scuffing (i) surface finish up gradation and utilize stiff } \\
\text { coatings, e.g. diamond-like carbon(DLC) coatings. (ii) Use of polished hardened and ground steel discs. } \\
\text { Hence, the improvementin surface finish not only improves scuffing resistance, but also reduces contact } \\
\text { friction and energy losses. }\end{array}$ & 5 & 9 & 6 & 270 \\
\hline BEARING & $\begin{array}{ll}\text { - } & \text { Overload } \\
\text { - } & \text { Profile } \\
\text { - } & \text { Fracks } \\
\text { - } & \text { Bendigue } \\
\text { - } & \text { Fretting } \\
& \text { Corrosion }\end{array}$ & $\begin{array}{l}\text { - Pitch control technology should be used in wind turbines which consist of sensors and electric motors } \\
\text { instead of conventional hydraulic system. Sensors measure wind potential and accordingly changes } \\
\text { blade's angle of attack turning blades out of the wind. It provides safety against overloads. } \\
\text { - Check up for bearing profile cracks using ultrasonic probe testing or acoustic instruments, vibro-acoustic } \\
\text { Modulation technique in particular. } \\
\text { - Fatigue bending can be reduced by introducing smart multi-function structures which adopts structural } \\
\text { health monitoring (SHM) including smart sensors, reinforced steel structures and data transmission } \\
\text { facilities. } \\
\text { - Time based maintenance methods should be incorporated. The relaxation in fasteners and bolted } \\
\text { components shouldbechecked after few hundred hours of operation. Spacers should be used to increase } \\
\text { the length of the bolt which reduces fretting wears. Friction shims should be used to reduce friction } \\
\text { between pressing surfaces. Regular checking and lubrication is must, as it reduces fretting. X-ray } \\
\text { diffraction is a method to check samples for presence of fretting but it is a costly affair. }\end{array}$ & 5 & 8 & 5 & 200 \\
\hline
\end{tabular}

\section{RESULTS}

The preventive measures for gear and bearing has been suggested in Table 2 corresponding to each type of failure mode. Risk priority number has been calculated based on provided values occurrence, severity and detection by the maintenance department. Figure 5 shows the comparison of three different factors involved in RPN i.e. occurrence, severity and detection before and after FMEA. Good improvement has been noticed in occurrence of particular faults after FMEA.

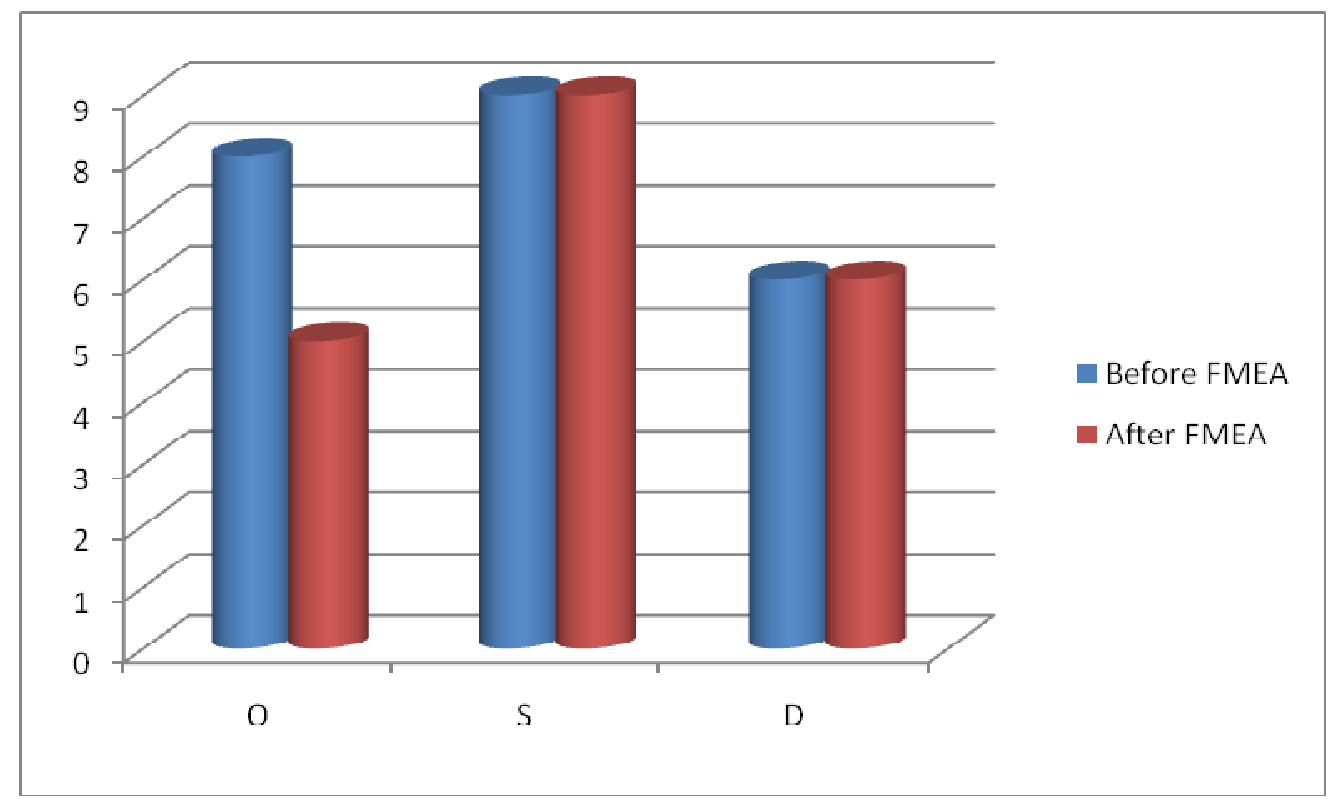

Figure 5: Occurrence, Severity \& Detection Before and After FMEA for Gear. 
Similarly Figure 6 shows comparison of Occurrence, Severity \& Detection before and after FMEA for Bearing. Here also, moderate reduction of occurrence of particular faults in bearing has been noticed.

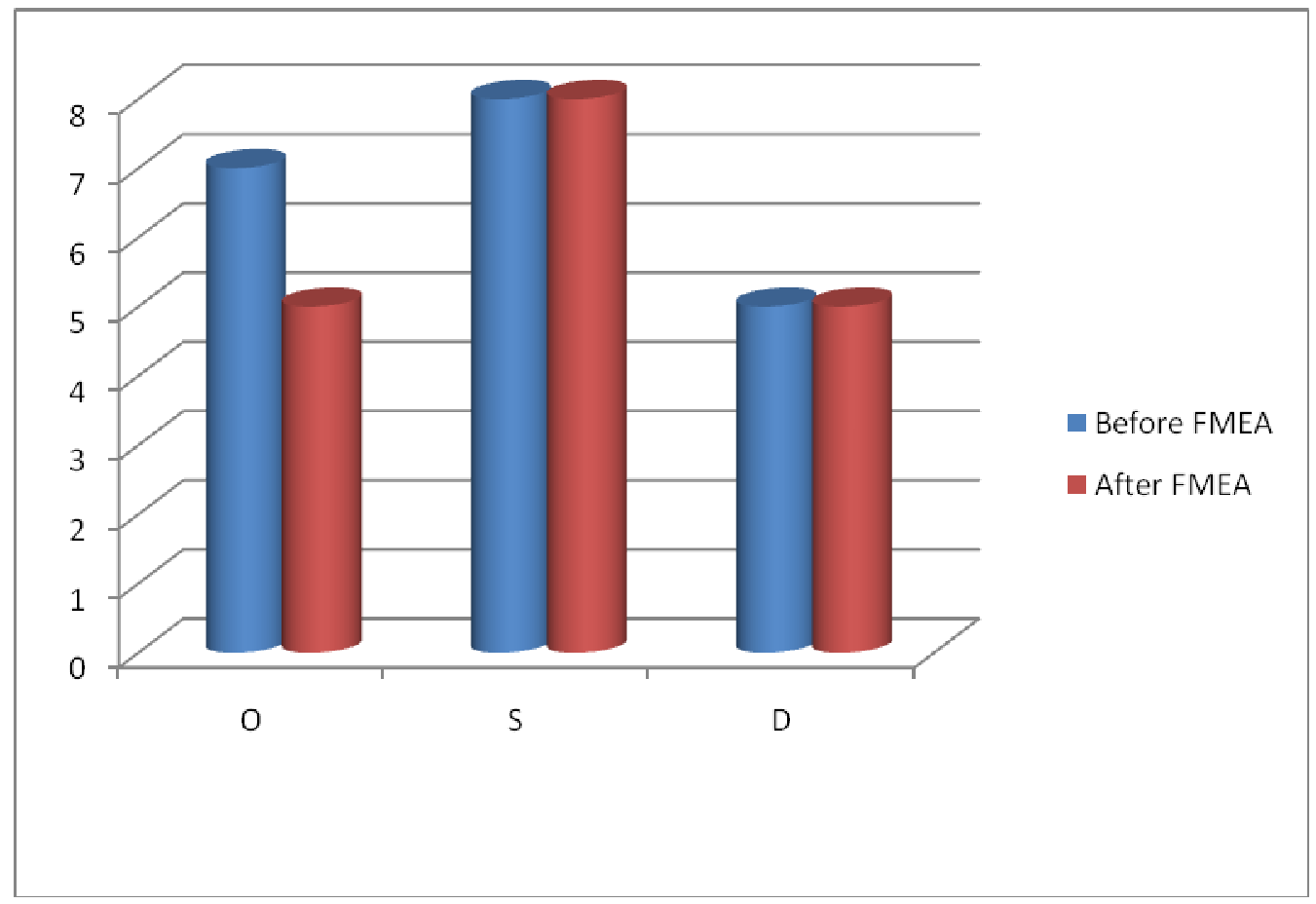

Figure 6: Occurrence, Severity \& Detection Before and After FMEA for Bearing.

Figure 7 indicates the final result which is comparison of risk priority number (RPN) pre and post FMEA for both the sub-components. Indubiously, RPN number has decreased to 270 against 432 for gear. For bearing, it has reduced to 200 against initial number of 280. Reduction in RPN, straightforwardly, indicates the decrease of possibility of failures.

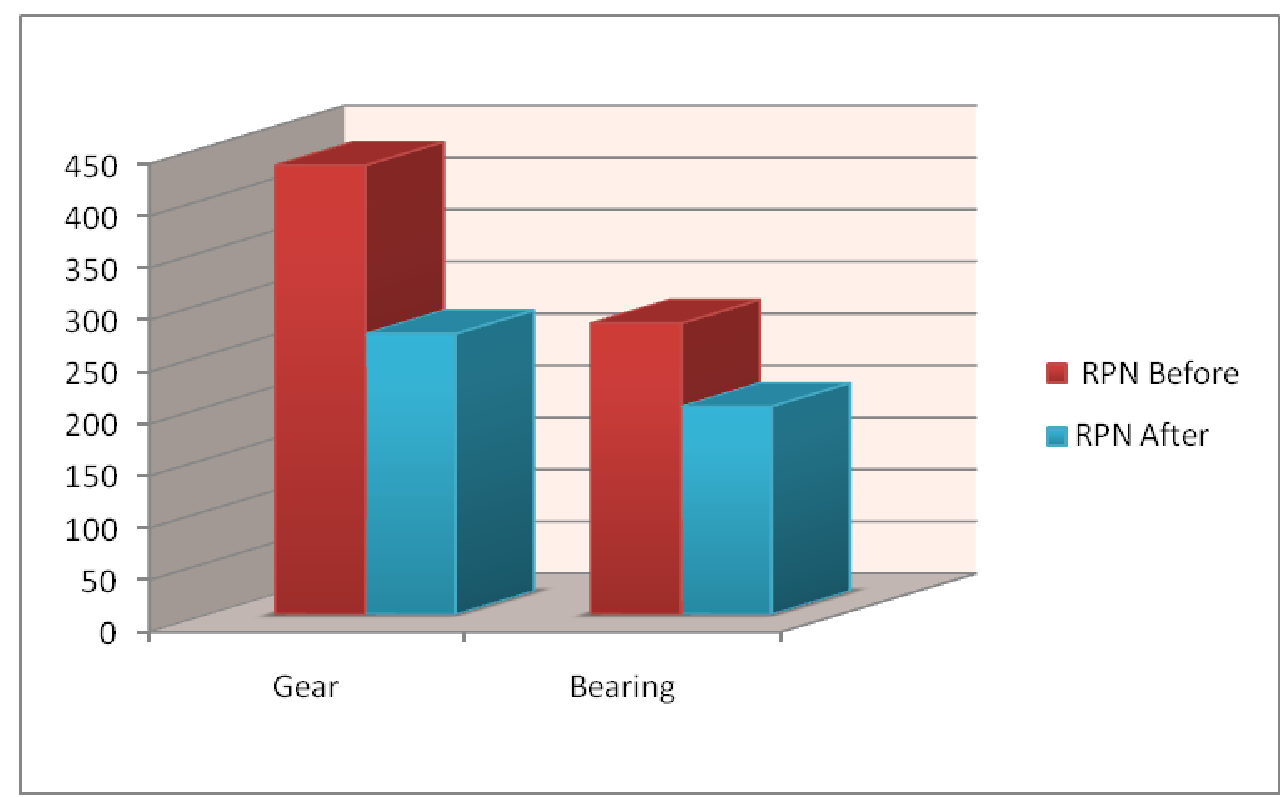

Figure 7: Comparison of RPN Pre and Post FMEA for Gear and Bearing.

This factor can also be depicted in terms of availability. The reduction of RPN means system will be more available. These results have been found in line with the findings of the other researchers also. 


\section{CONCLUSIONS}

FMEA is basically meant for supporting the maintenance engineers to enhance the reliability and availability of the system. The purpose of this paper is to show the practical applicability of FMEA which provides early identification of failures, removal of probable component failure modes, problem anticipation, and improved testing and development. Basic FMEA format has been proposed to the wind plant with remedial measures for various causes of failures of gear and bearing. Risk priority number has been calculated pre and post FMEA. Based on the remedial measure suggested, the proposed RPN has shown appreciable decline. This work encourages more research content and possibilities of exploring other components in same pattern for risk assessment.

\section{ACKNOWLEDGEMENT}

The authors are highly indebted and thankful to the Editor-in-Chief and reviewers for their constructive comments about this paper. The comments proved to be very resourceful and brought a marked improvement to the way in which this paper is structured.

\section{REFERENCES}

1. Silverman Mike \& Johnson, R. James. (2013). FMEA on FMEA. Annual Reliability and Maintainability Symposium (RAMS), DOI: 10.1109/RAMS.2013.6517629

2. Carla Estorlio \& Richard, K. Posso. (2010). The Reduction of Irregularities in the Use of Process FMEA. International Journal of Reliability Management, 27,24-27

3. Razi Farshad \& Hoseini Ehsan. (2017). Proposing a New Model of Failure Mode and Effect Analysis for Clustering and Ranking of Manufacturing Process. International Journal of Productivity and Quality Management, 21, 45-71

4. Xiuxu Zhao \& Yuming Zhu. (2010). Research of FMEA Knowledge Sharing Method Based on Ontology and the Application in Manufacturing Process. Proceeding of 2ndInternational Workshop on Database Technology and Applications (DBTA), 1-4

5. Bai, B. J., \& Kumar, C. R. (2014). Dynamic model and control of DFIG wind energy systems based on power transfer matrix using SVPWM. International Journal of Electrical and Electronics Engineering (IJEEE), 3 (1), 27, 36.

6. Nuchpho, P., \& Nansaarng, S. (2014). Risk Assessment in the Organization by Using FMEA Innovation. Proceedings of VII International Conference on Educational Reforms (ICER), 781-789

7. Kolios Athanasios, J. et al. (2017). Failure Mode and Effects Analysis Using a Fuzzy-TOPSIS Method: A Case Study of Subsea Module. International Journal of Multicriteria Decision Making,7, 29-53

8. Gilchrist, W. (1993). Modeling Failure Mode and Effect Analysis. International Journal of Quality and Reliability Management, 10, 16-23

9. Saifee, A., \& Mittal, A. R. V. I. N. D. (2014). Design of novel axial flux permanent magnet generator (AFPMG) for wind energy applications. Int J Electr Electr Eng Res, 4(3), 35-42.

10. Teng, S. H., \& Ho, S. Y. (1996). Failure Mode and Effects Analysis: An Integrated Approach for Design and Process Control. International Journal of Quality and Reliability Management, 13, 8-26

11. Kumar, A. P. et al. (2011). FMEA: Methodology, Design and Implementation in a Foundry. International Journal of Engineering Science and Technology, 3, 5288-5297 
12. Chatziangelou, M., \& Christaras, B. Rock Bolts and Shotcrete Effectiveness against Geological Failures. Application on Egnatia Highway in N. Greece.

13. Parsana, T. S., \& Patel, M. T. (2014). A Case Study: A Process FMEA Tool to Enhance Quality and Efficiency of Manufacturing Industry. International Journal of Industrial Engineering and Management Science, 4, 145-152

14. Guimaraes, A. C. et al. (2011). Fuzzy Methodology Applied to Probabilistic Safety Assessment for Digital System in Nuclear Power Plants. Nuclear Engineering Design,241, 3967-3976

15. Liu, H. T., \& Tsai, Y. L. (2012). A Fuzzy Risk Assessment Approach for Occupational Hazard in the Construction Industry. Safety Science, 50, 1067-1078

16. Arvanitoyannis, I. S. \& Barzakas, T. H. (2009). Application of Failure Mode and Effect Analysis and Cause and Effect Analysis for Industrial Processing of Common Octopus - Part II. International Journal of Food Science and Technology, 44, $79-92$

17. Rapinder Sawney. et al. (2010). A Modified FMEA Approach to Enhance Reliability of Lean System, International Journal of Reliability Management, 27, 143-150

18. Gary, S., \& Tang, S. (2006). Michael Ho Debra Shumar Paul C Lio, Implementing FMEA in a Collabrative Supply Chain Environment. International Journal of Reliability Management, 23, 1-6

19. Salimin, N., Jani, J., Ishak, N. A., Hassan, S., Elumalai, G., Boon, O. K., \& Shahril, M. I. (2014). Validity and Reliability Of Comprehensive Assessment Instruments For Professional Skills In Field And Court Sport Among Major Students Coaching Based On Model K.

20. Keskin Gulsin, \& Ozkan Cuskun (2009). An alternative evaluation of FMEA: Fuzzy Art Algorithm. Quality and Reliability Engineering International, 25, 647-661

21. Arabian-Hoseynabadi H. et al. (2010). Failure Modes and Effects Analysis for Wind Turbines. International Journal of Electrical Power and Energy Systems, 32, 817-824

\section{AUTHORS PROFILE}

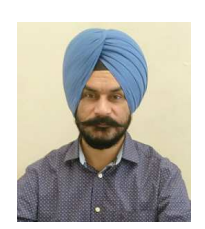

Dr. Navneet Singh Bhangu has 18 year of experience of providing knowledge resources to students and expertise in participatory and innovative teaching learning methodologies. He has done Ph.D from NIT, Kurukshetra and presently working as an Assistant Professor at Guru Nanak Dev Engineering College, Ludhiana. He has 51 papers published in various reputed international/national journals and conferences. He has attended and acted as resource person in various faculty development programs. He is also reviewer of 5 international journals. Author is life member of professional societies like ISTE, IIIE and IE (I). His areas of interest are reliability \& maintenance engineering, high voltage engineering and electrical machines. 


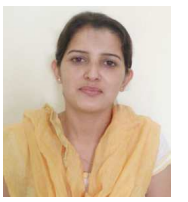

Er. Sonia Grover has received her B.Tech and M.Tech degree from IKGPTU University in 2010 \& 2012 respectively. She has 7 years of teaching experience and presently working as an Assistant Professor in Department of Electrical Engineering, Guru Nanak Dev Engineering College Ludhiana. Her area of research includes Renewable energy, Power system analysis, Smart grid, Power System Reliability. She has 17 papers published in various reputed international/national journals and conferences. 